\title{
A THREE DIMENSIONAL NON-HYDROSTATIC MODEL FOR TURBULENT AIR FLOW
}

\author{
DUONG NGOC HAI, NGUYEN THE DUC \\ Institute of Mechanics, NCST of Vietnam
}

\begin{abstract}
A finite-volume code is developed to compute the turbulent airflow over small-scale complex terrain. A pressure-correction algorithm is used to solve the threedimensional non-hydrostatic flow equations. The turbulent transport is simulated by the $k-\varepsilon$ model using some modifications suitable for atmospheric boundary-layer application.

As an example, the model is used to simulate the flow-field around a cubical building. The same flow as a towing-tank experiment of USEPA was simulated using our code. These simulations show that, the model was capable of simulating recirculation zones behind the building. The results of calculation are also compared with available measurement data.
\end{abstract}

\section{Introduction}

The determination of the turbulent wind field over complex terrain in the Atmospheric Boundary Layer has been a topic of numercus studies. Firstly, due to the mathematical difficulties involved in modeling the flow structure, the mean flow either has been assumed to be a simplified type of flow, or has been obtained by solving equations of motion with crude assumptions about turbulence [1]. Indeed, these models fail to reproduce certain important features of the complicated flow structures over complex terrain, especially when the terrain slope is steep. Consequently, it is now recognized that in order to understand how irregularities of the ground surface distort the mean and turbulent structure of the incident flow, it is necessary to solve the full set of fluid dynamics equations of mean properties using numerical methods.

Recent increases in computer power mean that numerical prediction of flow in complex terrain is now viable. Consideration of the equations of mean properties reduces the problem of turbulence closure. The application of first-order closure ( $K$ theory) has been widespread [2]. Nevertheless, in the convective boundary layers or for flow over the complex terrain, it is difficulty to express $K$ analytically, to measure it. Because of the extreme sensitivity of the turbulent field to the varying pressure gradients caused by the terrain, these models are not applicable 
to the case of complex terrain and thus a realistic description of the turbulent structure requires considerably more sophisticated closures.

In addition, most atmospheric models are based on the hydrostatic approximation [2]. In such models, pressure can be computed diagnostically in a simple manner from the hydrostatic assumption, but these models cannot numerically treat recirculating flows because the acceleration of the vertical velocity is neglected (see [3], [4], [5]). Martin and Pielke [6] also examined the adequacy of the hydrostatic assumption for sea breezes using a nonlinear numerical model with simple turbulence parameterizations. A general result from this study seems to be that the hydrostatic assumption becomes less valid as the synoptic temperature lapse rate becomes less stable.

The $k-\varepsilon$ model is the most widely used turbulence model in engineering fluid dynamics. In engineering applications, the $k-\varepsilon$ model has predicted recirculating flows with an accuracy acceptable for most purposes [7]. In this regard, a number of applications of the $k-\varepsilon$ model with some modifications have been attempted. in the atmosphere [2].

In this study, we solve a full set of primitive non-hydrostatic dynamic equations for mean flow quantities using a finite volume method. The code will be employed to perform the numerical calculations. The standard $k-\varepsilon$ model that consists of prognostic equations for the turbulent kinetic energy $k$ and the energy dissipation rate $\varepsilon$ are used. The performance of the model is evaluated through comparison of model results with tunnel data.

The remainder of this paper is organized as follows. The theoretical model, consisting of the governing equations and boundary conditions, is described in section 2. The numerical method is described in section 3. Computational results for flow are presented in section 4 . Finally, section 5 summarises the main conclusion of this work.

\section{Description of the model}

\subsection{Non-Hydrostatic flow model}

A full set of primitive non-hydrostatic dynamic equations is solved in this study. We neglect molecular diffusion in comparison with turbulent diffusion in the momentum equation, and confine our simulations to the atmospheric surface layer over a small domain (lets say $10 \times 10-\mathrm{km}$ ), so that Coriolis effects can also be

neglected. The governing equations, subject to an elastic assumption, Boussinesq approximations and Reynolds averaging are [8]: 
the continuity equation and the momentum equations:

$$
\begin{gathered}
\frac{\partial\left(\rho U_{i}\right)}{\partial x_{i}}=0 \\
\frac{\partial U_{i}}{\partial t}+U_{j} \frac{\partial U_{i}}{\partial x_{j}}=-\frac{\partial\left(\overline{u_{i}^{\prime} u_{j}^{\prime}}\right)}{\partial x_{j}}-\frac{1}{\rho_{0}} \frac{\partial \delta P}{\partial x_{i}}-\frac{\delta \rho}{\rho_{0}} g \delta_{i 3} ;
\end{gathered}
$$

the thermodynamic equation

$$
\frac{\partial \Theta}{\partial t}+U_{j} \frac{\partial \Theta}{\partial x_{j}}=-\frac{\partial\left(\overline{\theta^{\prime} u_{j}^{\prime}}\right)}{\partial x_{j}}
$$

where:

$\dot{U}_{i}$ is $i^{\text {th }}$ mean velocity component;

$i_{i}^{\prime}$ is $i^{\text {th }}$ turbulent fluctuation velocity component;

$\delta \rho$ is the deviation of density $\rho$ from its reference value $\rho_{0}$;

$\delta P$ is the derivation of pressure $P$ from its reference $P_{0}\left(P_{0}\right.$ and $\rho_{0}$ are the prescribed pressure and density, which correspond to a hydrostatic adiabatic fluid. For an ideal gas, their values are given by equation (2.7) and (2:8));

$\Theta$ is the mean potential temperature;

$\theta^{\prime}$ is the fluctuation of potential temperature.

and the state equation

$$
P=\rho R_{d} T
$$

with the definition of potential temperature

$$
\Theta=T\left(\frac{P}{P_{a}}\right)^{\frac{R_{d}}{C_{p}}}
$$

In the equations (2.4) and (2.5), $P_{a}$ is the surface pressure at $z=0, R_{d}$ is the gas constant for dry air $\left(R_{d}=287 \mathrm{Jkg}^{-1} \mathrm{~K}^{-1}\right)$ and $C_{p}$ is the specific heat at constant pressure for air.

For dry air. the isobaric specific heat $C_{p}$ has weak temperature dependence given by [2]:

$$
C_{p}=1005+(T-250)^{2} / 3364 J_{k g}^{-1} K^{-1} .
$$


The deep equation of Oruga and Philips [9] has been employed in the present. calculations for the base-state pressure and density

$$
\begin{aligned}
& P_{0}(z)=P_{a}\left(1-\frac{z}{H_{s}}\right)^{\frac{C_{p}}{R_{d}}}, \\
& \rho_{0}(z)=P_{a} \frac{\left(1-\frac{z}{H_{s}}\right)^{\frac{o_{p}}{R_{d}}-1}}{R_{d} \Theta},
\end{aligned}
$$

where $H_{s}\left(=\frac{C_{p} \Theta}{g}\right)$ is the isentropic scale height.

In the driving (2.7) and (2.8) the ideal gas law (Equation (2.4)), the definition of potential temperature (Equation (2.5)) and the hydrostatic balance relation $\frac{d P}{d z}=-\rho g$ were applied to the reference state variables.

\subsection{The turbulence closure schemes}

The Reynold stresses in Equation (2.2) and heat fluxes in Equation (2.3) have frequently been modeled or parameterized using the gradient transport relations to close the above system of equations.

The $k-\varepsilon$ turbulent model is used to close the above system [7]. In this scheme, the Reynold stresses and heat fluxes are computed from the eddy viscosity assumption:

$$
\begin{aligned}
\overline{u_{i}^{\prime} u_{j}^{\prime}} & =-\nu_{t}\left(\frac{\partial U_{i}}{\partial x_{j}}+\frac{\partial U_{j}}{\partial x_{i}}\right)+\frac{2}{3} \delta_{i j} k, \\
\overline{u_{i}^{\prime} \theta^{\prime}} & =-\frac{\nu_{t}}{\sigma_{t}} \frac{\partial \Theta}{\partial x_{i}},
\end{aligned}
$$

where $\nu_{t}$ is the eddy viscosity, $\sigma_{t}$ is the turbulent Prandtl number and $k$ is the turbulent kinetic energy (TKE).

The eddy viscositity is given by:

$$
\nu_{t}=c_{\mu} \frac{k^{2}}{\varepsilon},
$$

where $c_{\mu}$ is a constant and $\varepsilon$ is the dissipation rate of turbulent kinetic energy.

The transport equations for the turbulent kinetic energy $k$ and dissipation rate $\varepsilon$ are

$$
\begin{aligned}
& \frac{\partial k}{\partial t}+U_{j} \frac{\partial k}{\partial x_{j}}=\frac{\partial}{\partial x_{j}}\left(\frac{\nu_{t}}{\sigma_{k}} \frac{\partial k}{\partial x_{j}}\right)+S+G-\varepsilon \\
& \frac{\partial \varepsilon}{\partial t}+U_{j} \frac{\partial \varepsilon}{\partial x_{j}}=\frac{\partial}{\partial x_{j}}\left(\frac{\nu_{t}}{\sigma_{\varepsilon}} \frac{\partial \varepsilon}{\partial x_{j}}\right)+\frac{\varepsilon}{k}\left(c_{1 \varepsilon} S+c_{3 \varepsilon} G-c_{2 \varepsilon} \varepsilon\right)
\end{aligned}
$$


where $\sigma_{k}, \sigma_{\varepsilon}, c_{1 \varepsilon}, c_{2 \varepsilon}$ and $c_{3 \varepsilon}$ are constants, $S$ is the shear production term and $G$ is the buoyancy term in the TKE equation, defined as

$$
\begin{aligned}
& S=\nu_{t}\left(\frac{\partial U_{i}}{\partial x_{j}}+\frac{\partial U_{j}}{\partial x_{i}}\right) \frac{\partial U_{i}}{\partial x_{j}}, \\
& G=\frac{\nu_{t}}{\sigma_{t}} \frac{g}{\rho_{0}} \frac{\partial \rho}{\partial z} .
\end{aligned}
$$

In the above equations, the following standard values of the constants, which have been used for most engineering applications are:

$$
c_{\mu}=0.09, C_{1 \varepsilon}=1.44, c_{2 \varepsilon}=1.92, C_{3 \varepsilon}=1.44, \sigma_{k}=1.0, \sigma_{\varepsilon}=1.13, \sigma_{t}=0.9 \text {. }
$$

The standard $k-\varepsilon$ model is the most widely used turbulence model in engineering fluid dynamics. In the atmospheric turbulence modeling, some authors recommended making some changes to the standard $k-\varepsilon$ model: Raithy et al. [10] set $c_{\mu}=0.033$ in their three-dimensional simulation of airflow over Askervein Hill. Detering and Etling [11] recommended making two changes in the standard $k-\varepsilon$ model. The first change also was a modification of the $c_{\mu}$ constant. They noted that the equivalent constant for similar measurements [12] in the surface layer of the atmospheric boundary layer $(\mathrm{ABL})$ was $c_{\mu}=0.026$. In the second modification, Detering and Etling suggested modifying the $\varepsilon$ equation to better reflect characteristic turbulent length scale above the region of strong shear in the atmospheric boundary layer. They proposed reducing $\varepsilon$ by modifying the $c_{1 \varepsilon}$ constant. They used a modified constant $c_{1 \varepsilon}^{\prime}$, such that

$$
c_{1 \varepsilon}^{\prime}=\frac{c_{1 \varepsilon} L}{h}
$$

where $L$ are the scales of the dominant turbulent eddies and $h$ is a characteristic scale for the atmospheric boundary layer.

The $k-\varepsilon$ turbulence models assume that the scales of the dominant turbulent eddies are given by

$$
L=\frac{c_{\mu}^{3 / 4} k^{3 / 2}}{\varepsilon} .
$$

The characteristic scale for the atmospheric boundary layer $h$ given as

$$
h=c_{k} \frac{u_{*}}{f},
$$

where $u_{*}$ is the friction velocity, $f$ is the Coriolis parameter, and $c_{h}$. is an empirical constant, which was set by Deterring and Etling to an optimum value of 0.0015 . 
The modifications of Detering and Etling to the standard engineering $k-\varepsilon$ were incorporated into our code.

\subsection{Boundary Conditions and Initialization}

Equations (2.1), (2.2) (3 equations), (2.3), (2.4), (2.12) and (2.13) constitute 8 equations for the 8 field variables $U_{i}$ (3 variables), $P, \rho, \Theta, k$ and $\varepsilon$. In the following section, for convenience, we shall use $u, v, w$ instead of the mean velocity components $U_{i}$.

The incoming flow (in the $x$ direction) is characterized by a velocity profile. At the inflow boundary, variables are kept constant in time as:

$$
\begin{aligned}
& u=U_{0}(z), \\
& v=w=0 .
\end{aligned}
$$

In a neutrally stratified surface layer, the wind profile is predicted and observed to vary logarithmically with height

$$
U_{0}(z)=\frac{u_{*}}{k} \ln \left(\frac{z}{z_{0}}\right),
$$

where $u_{*}$ is friction velocity, $k=0.4$ is Von-Karman constant, and $z_{0}$ is the aerodynamic roughness length. In non-neutral conditions the profile expression for wind is modified by a non-dimensional function $\phi_{M}$ of height and stability $[2$, 13].

At the lower boundary $\left(z=z_{0}\right), u=v=w=0$. At the lateral boundary, upper boundary and outflow boundary, the gradient of velocity components normal to the boundary is set equal to zero.

It has often been observed that potential temperature profiles follow surfacelayer-similarity, which tends to a constant-gradient form $[2,14,15]$,

$$
\Theta_{0}(z)=\Theta_{s o i l}+\left(\frac{d \Theta}{d z}\right)_{\infty} z \text {. }
$$

Aspley et al [16], from an experiment of USEPA, estimated $\left(\frac{d \Theta}{d t}\right)_{\infty}=2.98 \times$ $10^{-2} \mathrm{Km}^{-1}$. They also suggested the following modification for equation (2.22):

$$
\Theta_{0}(z)=\Theta_{s o i l}+\left(\frac{d \Theta}{d z}\right)_{\infty}\left(z+\frac{L}{5} \ln \frac{z}{z_{0}}\right),
$$

where $L$ is the Monin-Obukhov length, $L=33 \mathrm{~m}$ in his study. Equation (2.23) was used in our model as the initial condition for potential temperature. 
The equations (2.7) and (2.8) are used as the initial conditions for pressure and density. At all of the boundaries, the normal derivative of temperature, pressure and density are set equal to zero.

For $k$ and $\varepsilon$, the lower boundary conditions are applied at some height $z_{p}$ within the surface layer

$$
\begin{aligned}
& k\left(z_{p}\right)=\frac{u_{*}^{2}}{c_{\mu}^{1 / 2}}, \\
& \varepsilon\left(z_{p}\right)=\frac{u_{*}^{3}}{k z_{p}},
\end{aligned}
$$

where $z_{p}$ is chosen as the half-grid level above the ground. These boundary condition for $k$ and $\varepsilon$ result from assuming that dissipation near the ground is balanced by the generation of turbulent kinetic energy [17]. This assumption is used here in the absence of better boundary conditions. At the inflow boundary, variables are kept constant in time as

$$
\begin{aligned}
& k(z)=k_{0}(z), \\
& \varepsilon(z)=\varepsilon_{0}(z),
\end{aligned}
$$

where $k_{0}(z)$ and $\varepsilon_{0}(z)$ are the output profiles from the simulations carried out in flat terrain. While running the simulations in flat terrain, the simulation domain was set sufficiently large in the flow direction in order for the flow to develop and finally reach equilibrium.

At the outflow boundary and lateral boundary, the gradient of $k$ and $\varepsilon$ normal to the boundary is set equal to zero [18].

\section{Numerical method}

The three-dimensional numerical calculations described in this paper were performed with the finite volume discretization. A pressure-correction scheme is used to solve the primitive-variable equations.

In the finite-volume method the conservative equations-each of the canonical form:

$$
\frac{\partial}{\partial t}(\rho \phi)+\nabla \cdot(\rho u \phi)=\nabla \cdot(\Gamma \nabla \phi)+S
$$

are discretised in integral form over control volumes making up the flow domain.

In the equation (3.1): $\phi$ can be $u, v, w, \Theta, k$ or $\varepsilon$; $\Gamma$ denote the diffusion coefficient, and $S$ is the source of $\phi$. 
In the present study, the value of $\phi$ on the control volume face is determined by the second-order upwind scheme of Patankar [19] and the gradients of $\phi$ in the diffusive flux are treated in the standard fashion by centered differencing.

Using Cartesian velocity decomposition and staggered velocity storage, the discretised equations for velocity component $U_{i}$ can be written in normalized form:

$$
U_{p}^{i}-\sum_{d} a_{p+d}^{\prime} U_{p+d}^{\prime}=d_{p}^{\prime}\left(P_{p-i}-P_{p}\right)+b_{p}^{i}
$$

where, subscript $p+d$ describe the node in direction $d$ from node $p$.

Pressure-correction schemes use an approximate linear relationship between velocity and pressure corrections:

$$
U_{p}^{i^{\prime}}=\delta_{p}^{i}\left(P_{p-i}^{\prime}-P_{i}^{\prime}\right)
$$

and invoke mass conservation to derive a pressure-correction field steering the solution towards continuity.

Matrix equations of form (3.2) are solved by line-iteration procedures in conjunction with a tridiagonal solver.

Staggered storage prevents "order-even" pressure node decoupling and permits the use of pressure-correction schemes as SIMPLE, SIMPLER, SIMPLEC. In our code, SIMPLE method was used, Patankar [19] gives a detailed specification of this method.

The most important difference is that two new partial differential equations for $k$ and $\varepsilon$ need to be solved. According to Ferziger [7], because the time scales associated with the turbulence are much shorter than those connected with the mean flow, the equations for $k$ and $\varepsilon$ are much stiffer than the flow equations. For this reason, in the numerical solution procedure, one first performs an outer iteration of the momentum and pressure correction equations in which the value of the eddy viscosity is base on the values of $k$ and $\varepsilon$ at the end of the preceding iteration. After this has been completed, an outer iteration of the turbulent kinetic energy and dissipation equations is made. After completing an iteration of the turbulence model equations, we are ready to recalculate the eddy viscosity and start a new outer iteration.

\section{Results of numerical simulation}

Thomson and Lombardi $[20,21]$ have carried out a wind tunnel study. They measured the velocity and turbulence intensity in the longitudinal direction. The 
wind tunnel model was a $0.187 \mathrm{~m}$ cube placed in a $1.8 \mathrm{~m}$ deep simulated neutral atmospheric boundary layer with a wind speed of $1.46 \mathrm{~ms}^{-1}$ at the building height. The velocity without the building followed the one-seventh-power law with elevation $z$ measured from a plane $0.025 \mathrm{~m}$ above the floor of the tunnel and $0.025 \mathrm{~m}$ below the top of the roughness elements. The same flow was simulated using our code.

A variable mesh was used in order to increase the resolution in regions where gradients are large. Our numerical simulation used a variable-spaced grid of 62 nodes length, 45 nodes width and 32 nodes height. The building was 7 nodes long $\times 7$ nodes wide $\times 8$ nodes high. Figure 1 shows the top view and the side view of

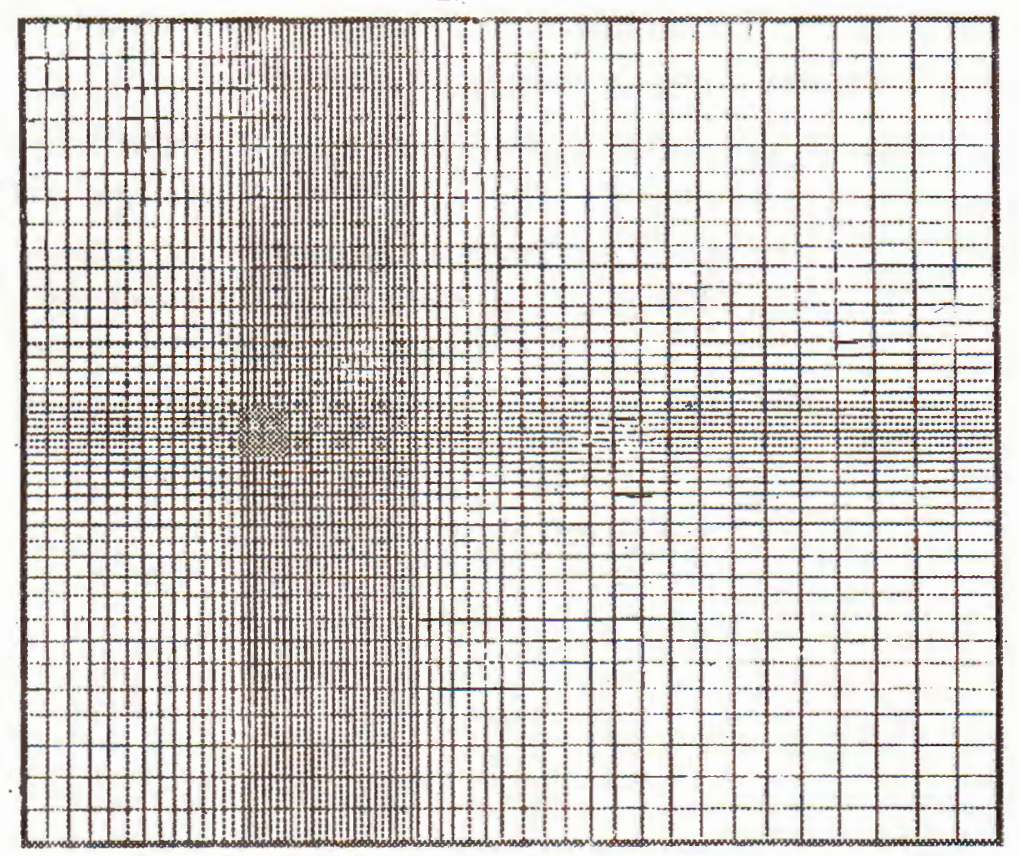

(a): Top view

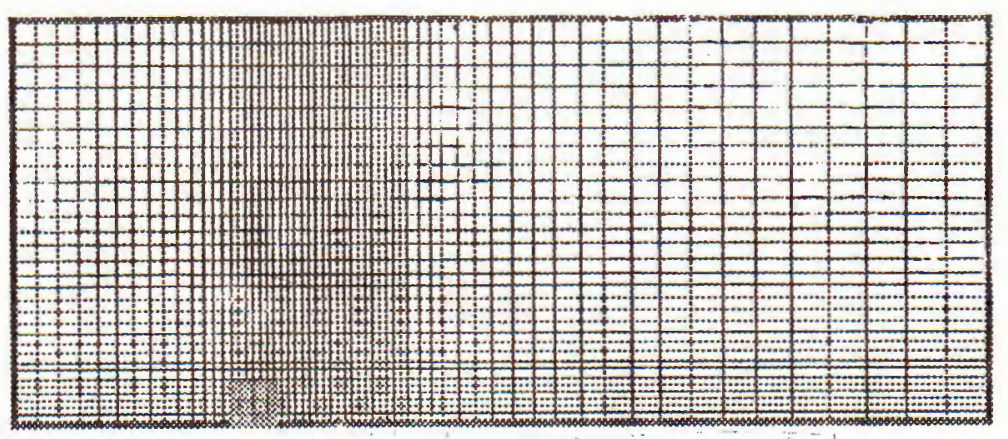

(b): Side view

Fig. 1. Grid used in the simulation 
the grid. The limits of the horizontal axis (in the longitudinal direction) are $x=-5.6 \mathrm{H}$ and $x=17.4 \mathrm{H}$, where $x$ is measured from center of the building. The limits of the lateral axis are $y=-9.8 H$ and $y=9.8 H$, where $y$ is measured from the center of the building, $H=0.187$. The limits of the vertical axis are $z=0$ and $z=9.675 H$.

With the average time step of $\delta t=0.1 s$, approximately $5 \mathrm{~h}$ of CPU time on the PC-INTEL CELERON $400 \mathrm{MHz}$ is required to reach steady-state solution. Each run corresponds to approximately $0.2 \mathrm{~min}$ of real-time.

Figure 2 and Figure 3 show the downwind velocity profiles at two locations and compare the computed results with the wind tunnel simulation. From the figures it can be seen that the calculation results fit fair measurement data and the difference between them has the order smaller than 7 .

The velocity field in the vertical plane through the center of the building is shown in Figure 4, and the velocity vector field in the horizontal plane above the midpoint of the building $(z=0.7 \mathrm{H})$ is shown in Figure 5 . The limits of the vertical axis are $z=0$ and $z=2 H$. The limits of the $x$ axis are $x=-2 H$ and $x=4 H$. The limits of the $y$ axis are $y=-1.5 H$ and $y=1.5 H$. The recirculation zone behind the building can be seen in these figures. The length of the recirculation zone behind the building was about $2 H$.

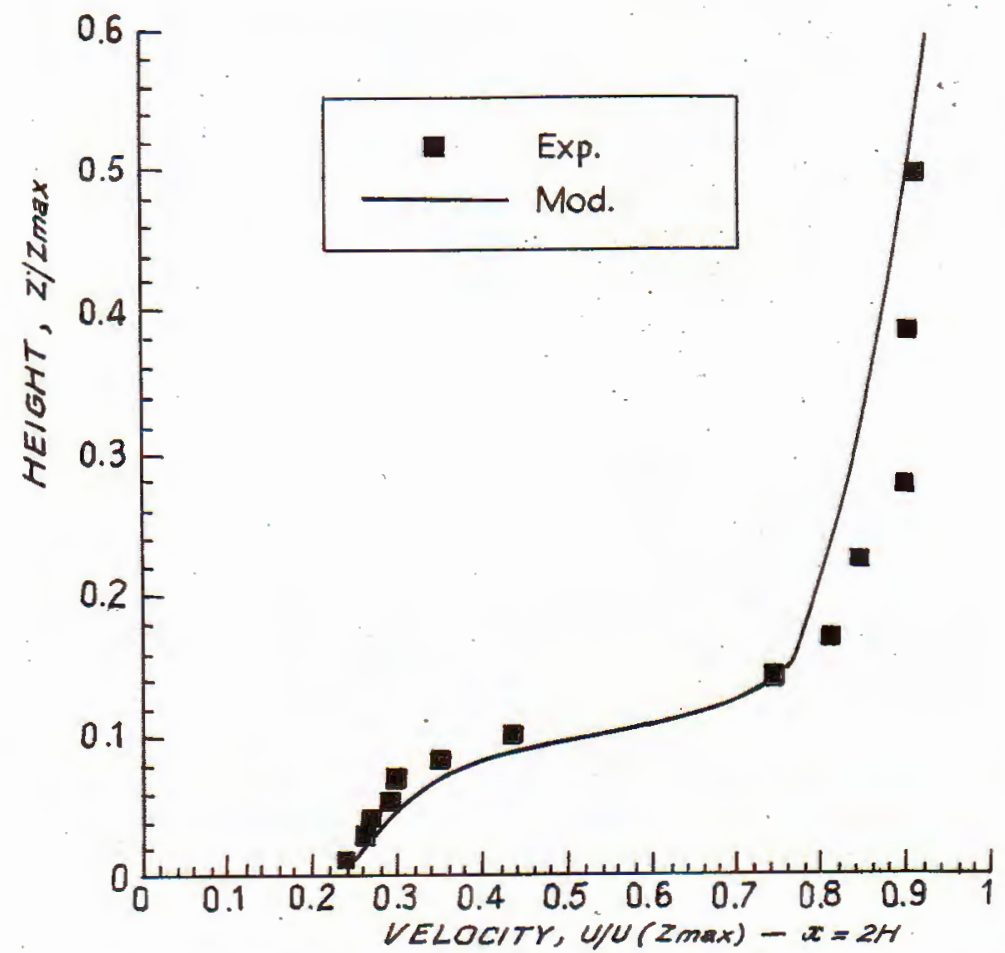

Fig. 2. Mean velocity profiles for experimental and simulated results at $x=2 H$ and $y=0$ 


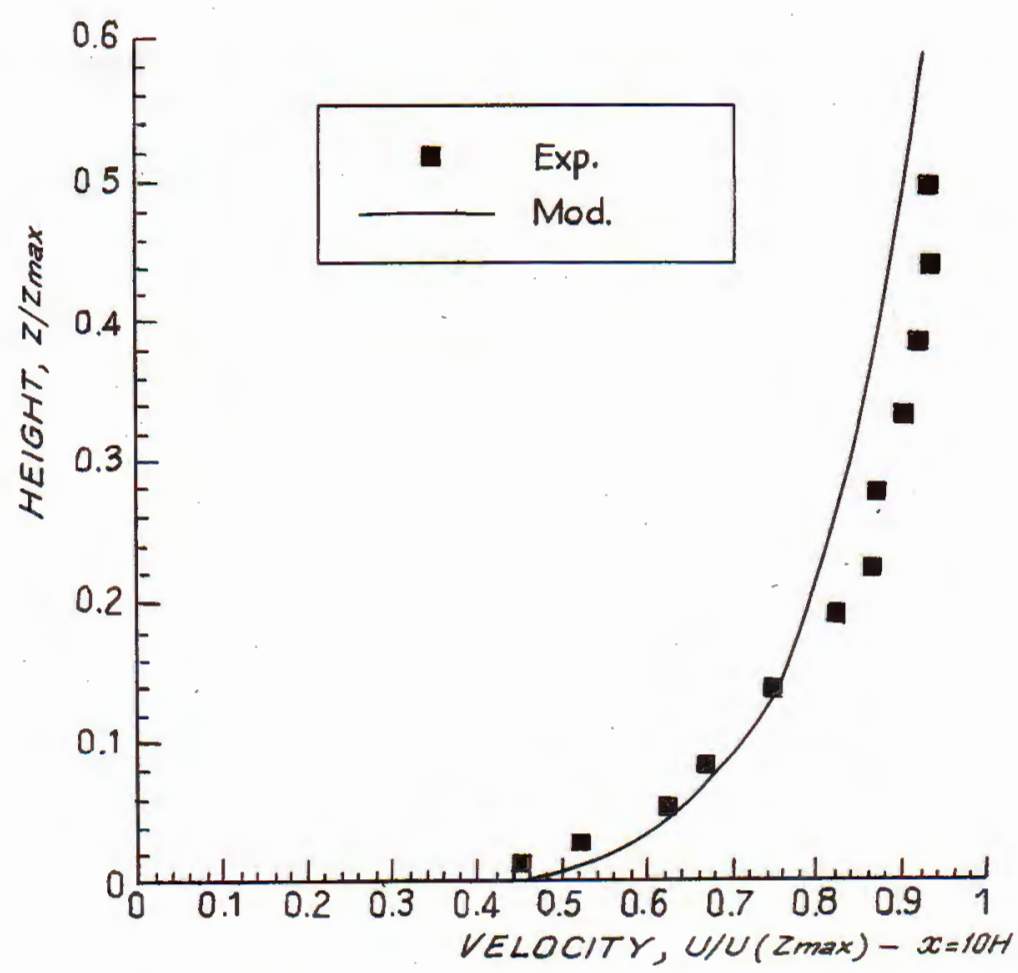

Fig. 3. Mean velocity profiles for experimental and simulated results at $x=10 H$ and $y=0$

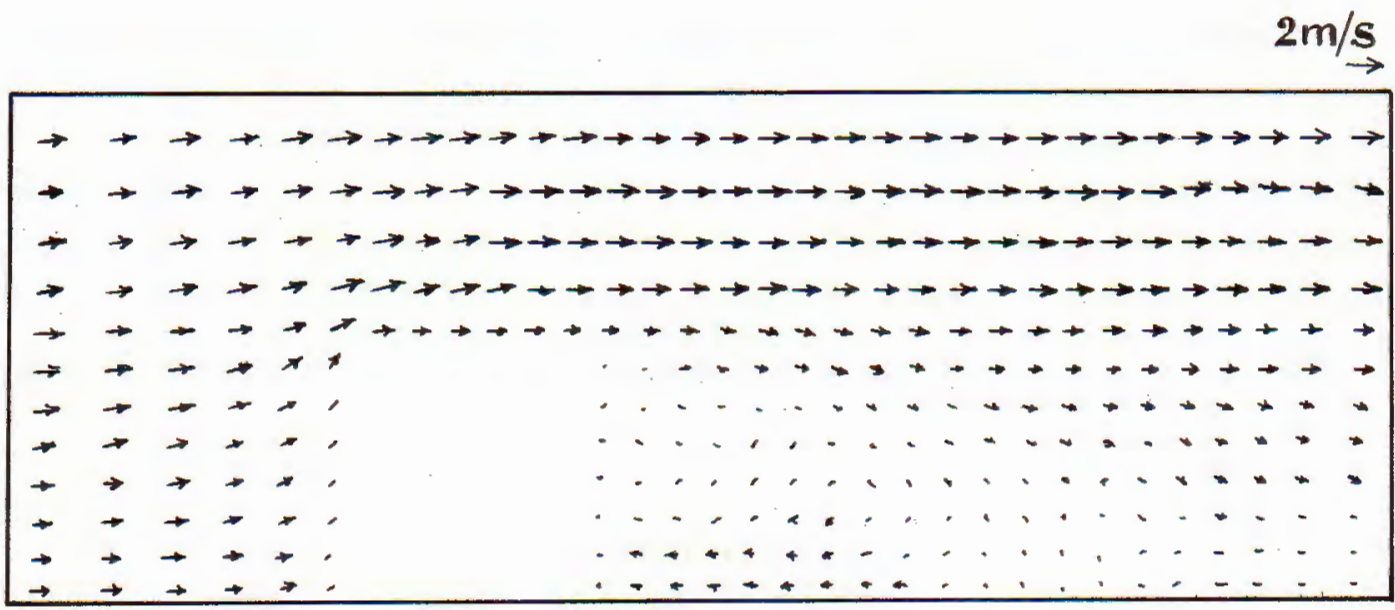

Fig. 4. Velocity vector field in the vertical plane at the center of the building 


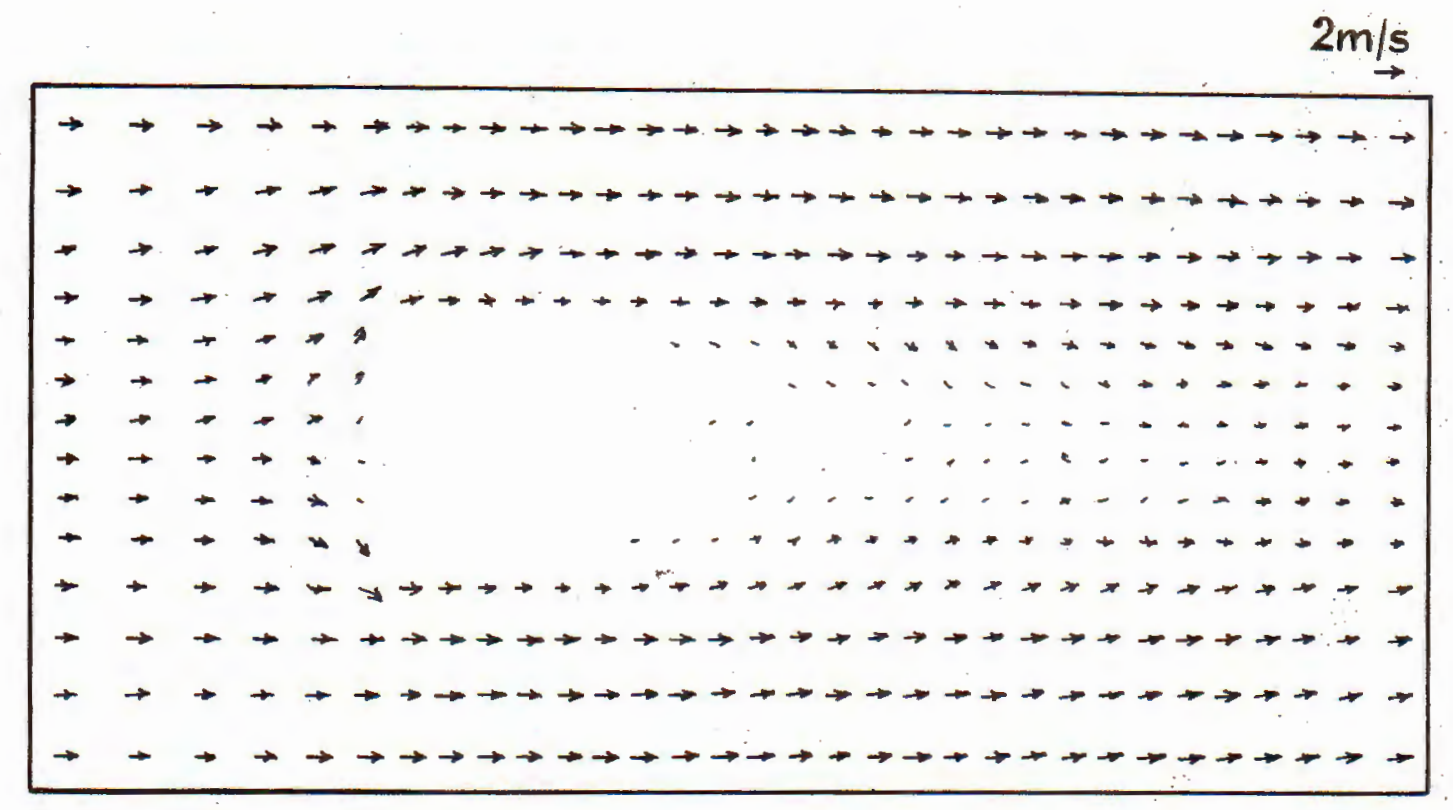

Fig. 5. Velocity vector field in the horizontal plane $z=0.7 H$

\section{Conclusions}

The purpose of this research was to develop a three-dimensional numerical code to model the atmospheric transport over small-scale complex terrains, This code, incorporating a'more accurate turbulence closure model than normally used in the atmosphere, was developed for simulations of flow over complex terrain. The code, designed with a proven engineering turbulence model, was capable of simulating recirculation zones and flows with buoyancy effects. From the results of the numerical simulations compared with available measurements, the turbulence models in this research appeared to be sufficiently accurate.

The research is supported by the National Basic Research Program in Natural Sciences.

\section{REFERENCES}

1. Schiermeier F. A. et al. Meteorological events that produced the highest ground-level concentrations during complex terrain/field experiments. In Air Pollution Modeling and Its Application V. Ed. by Wispelaere C. D. et al. Plenum Press, New York, 1985, pp.99-111. 
2. Garrat J. R. The atmospheric boundary layer. Cambridge University Press, New York, 1992.

3. Duong Ngoc Hai, Nguyen The Duc. LADM model-Mesoscale wind field and pollutant propagation in the air simulation. Proceedings of Fourth National Conference in Fluid Mechanics, Hanoi, 12/1995.

4. Duong Ngoc Hai, Nguyen The Duc. Assess the predicted air quality impacts arising from operation of the proposed Quang Ninh Thermal Power Plant. Proceedings of the Sixth National Conference of Mechanics, Hanoi, 1997.

5. Duong Ngoc Hai, Nguyen Van Diep, Nguyen The Duc, Le Trinh. Wind field over complex terrain and air quality modeling. J. of Mechanics, NCST of Vietnam, T.XIX, No 4, 1997, pp.29-38.

6. Martin C. L. and Pielke R. A. The adequacy of the hydrostatic assumption in sea breeze modelling over flat terrain. J. Atmos. Sci. Vol. 40, 1983, pp.14721481.

7. Ferziger J. H. and M. Perié. Computational methods for fluid dynamics. Springer-Verlag Berlin Heidelberg, 1996.

8. Dutton J. A. and Fichtl G. H. Approximate equations of motions for gases and liquids. J. Atmos. Sci. Vol.26, 1969, pp. 241-254.

9. Clack T. L. A Small-scale dynamic model using a terrain-following coordinate transformation. J. Comp. Phys. Vol. 24, 1997, pp. 186-215.

10. Raihby G. D., Stubley G. D. and Taylor P. A. The Askervain Hill project: A finite control volume prediction of three-dimensional flows over the hill, Bound. Layer Meteor. Vol. 39, 1987, pp. 247-367.

11. Detering H. W. and Etling D. Application of the $E-\varepsilon$ turbulence model to the atmospheric boundary layer. Bound. Layer Meteor. Vol.33, 1985, pp. 113-133.

12. Panofsky H. A., Tennekes H., Lenschow D. H. and Wyngaard J. C. The characteristic of turbulent velocity components in the surface layer under convective conditions. Bound. Layer Meteor. Vol. 11, 1977, pp.355-361.

13. Tennekes H. The logarithmic wind profile. J. Atmos. Sci. Vol.30, 1973, pp. 234-238.

14. Koo Y. S. and Reible D. D. Flow and transport modeling in the sea-breeze Part I: Flow model application and pollutant transport. Bound. Layer Meteor. Vol. 75, 1995, pp. 209-234.

15. Koo Y. S. and Reible D. D. Flow and transport modeling in the sea-breeze 
Part I: A modified $E-\varepsilon$ model with a non-equilibrium level 2.5 closure. Bound. Layer Meteor. Vol. 75, 1995, pp. 109-140.

16. Aspley D. D. and Castro I. P. Numerical modeling of flow and dispersion around cinder cone butte. J. Atmos. Environ. Vol. 31, No 7, 1997, pp. 10591071.

17. Ying R. et al. Numerical simulation of flow data over two-dimensional Hills. Bound. Layer Meteor. Vol.70, 1994, pp.401-427.

18. Gross G. A. Numerical study of the air flow within and around a single tree. Bound. Layer Meteor. Vol.40, 1987, pp.311-327.

19. Patankar S. V. Numerical heat transfer and fluid flow. McGraw-Hill, New York, 1980.

20. Dawson P., Stock D. E. and Lamb B. The numerical simulation of airflow and dispersion in three-dimensional atmospheric recirculation zones. J. Applied Meteorology Vol. 30, 1991, pp.1005-1024.

21. Thomson R. S. and Lombardi D. J. Dispersion of rooftop emission from isolated buildings: A wind tunnel study, EPA-600/4-77-006. United States Environmental Protection Agency, 36pp., 1977.

Received August \&, 2000

\section{MộT MÔ HìnH PHI THƯY TĨNH BA CHIỀU CHO DÒNG RỐI KHÍ QUYỂN}

Một chương trình tính toán sử dụng sai phân thể tích hữu hạn được phát triển để mô phóng dòng rối khí quyển qua những vùng địa hình phức tạp có kích cỡ nhó. Hệ phương trình dòng phi thủy tĩnh ba chiều được giải bằng thuật toán hiệu chỉnh áp suất. Chuyển động rối được mô phơng bằng mô hình $k-\varepsilon$ với một số thay đồi phù hợp với lớp biên khí quyển.

Như một ví dụ minh họa, chương trình được sử dụng để mô phỏng trường dòng quanh một vật cán hình hộp. Cùng một dòng như một thí nghiệm của US EPA được mô phỏng số băng chương trình này. Các tính toán thấy rằng, mô hình có khả năng mô phỏng vùng xoáy sau vật cản. Kết quả tính toán cũng được so sánh với các số liệu đo đạc của thí nghiệm. 